\title{
Ermin, A Myelinating Oligodendrocyte-Specific Protein That Regulates Cell Morphology
}

\author{
Damian Brockschnieder, ${ }^{1}$ Helena Sabanay, ${ }^{1}$ Dieter Riethmacher, ${ }^{2}$ and Elior Peles ${ }^{1}$ \\ ${ }^{1}$ Department of Molecular Cell Biology, The Weizmann Institute of Science, Rehovot 76100, Israel, and 'Zentrum für Molekulare Neurobiologie, Hamburg \\ University, 20251 Hamburg, Germany
}

\begin{abstract}
Oligodendrocytes form an insulating multilamellar structure of compact myelin around axons, thereby allowing rapid propagation of action potentials. Despite the considerable clinical importance of myelination, little is known about the molecular mechanisms that enable oligodendrocytes to generate their specialized membrane wrapping. Here, we used microarray expression profiling of oligodendrocyte-ablated mutant mice to identify new glial molecules that are involved in CNS myelination. This effort resulted in the identification of Ermin, a novel cytoskeletal molecule that is exclusively expressed by oligodendrocytes. Ermin appears at a late stage during myelination, and in the mature nerves, it is localized to the outer cytoplasmic lip of the myelin sheath and the paranodal loops. In cultured oligodendrocytes, Ermin becomes visible in well differentiated MBP-positive cells, where it is concentrated at the tip of F-actinrich processes (termed "Ermin spikes"). Ectopic expression of Ermin, but not of a mutant protein lacking its actin-binding domain, induced the formation of numerous cell protrusions and a pronounced change in cell morphology. Our results demonstrate that Ermin is a novel marker of myelinating oligodendroglia and suggest that it plays a role in cytoskeletal rearrangements during the late wrapping and/or compaction phases of myelinogenesis.
\end{abstract}

Key words: myelin; oligodendrocytes; cytoskeleton; ERM proteins; cell ablation; cytoarchitecture

\section{Introduction}

To allow efficient and rapid propagation of action potentials, oligodendrocytes (OLs) form multiple myelin segments by spirally wrapping their membrane around the axons. During development, oligodendrocytes first send multiple filopodia that contact and ensheath axons (Butt and Berry, 2000). After this initial loose ensheathment, non-ensheathing processes are removed and spiral wrapping of the axon commences, eventually forming the compact myelin. Although likely to be controlled by the cell cytoskeleton, it is not clear how oligodendrocytes undergo the substantial morphological changes during the different phases of myelination (i.e., axonal recognition, ensheathment, process retraction, wrapping, myelin compaction, and elongation of the myelin unit). The cytoskeleton of oligodendrocytes contains microtubules and microfilaments but appears to be devoid of intermediate filaments (Wilson and Brophy, 1989; Pfeiffer et al., 1993). In cultured oligodendrocytes, microtubules predominantly reside in the cell body and main processes, whereas microfilaments are organized as an extensive network that extends from the cell body into peripheral branches and thin villi (Song et al., 2001). Here, we report on the identification of a new

Received 0ct. 11, 2005; accepted Nov. 22, 2005.

This work was supported by the Israel Academy of Science and by a postdoctoral fellowship to D.B. from "Deutsche Akademie der Naturforscher Leopoldina," the German Federal Ministry of Education and Research (BMBF-LPD 9901/8-104). E.P. is Incumbent of the Madeleine Haas Russell Career Development Chair. We thank Klaus-Armin Nave for the CNP-Cre mice and Eva Kentrup for her support and encouragement.

Correspondence should be addressed to Dr. Elior Peles, Department of Molecular Cell Biology, The Weizmann Institute of Science, Rehovot 76100, Israel. E-mail: peles@weizmann.ac.il.

DOI:10.1523/JNEUROSCI.4317-05.2006

Copyright $\odot 2006$ Society for Neuroscience $\quad 0270-6474 / 06 / 260757-06 \$ 15.00 / 0$ oligodendrocyte-specific cytoskeletal protein that may play an important role in shaping the specialized architecture of CNS myelin.

\section{Materials and Methods}

RNA isolation, cRNA probe synthesis, and DNA microarray hybridization. Oligodendrocyte-ablated animals were obtained by crossing CNP-Cre mice (Lappe-Siefke et al., 2003) with a Rosa26-lacZ ${ }^{\text {flox }}$ DTA mice, in which an additional polyadenylation stop signal was introduced upstream of the loxP-DTA gene described previously (Brockschnieder et al., 2004). Total RNA was isolated with TRIzol reagent (Invitrogen, San Diego, CA) from dissected brainstems of 11-d-old animals. Independent RNA samples from three mutant (CNP-Cre $+/-$, Rosa26-lacZ ${ }^{\text {flox }}$ DTA

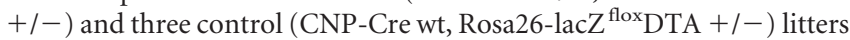
were subsequently processed according to the GeneChip protocol (Affymetrix, Santa Clara, CA).

Plasmids and antibodies. The open reading frame of Ermin was cloned from mouse and rat brains cDNA by PCR. The sequences obtained matched to database sequences (NM_029972 and NM_001008311). The $\mathrm{N}$-terminal Myc-tagged expression constructs of Ermin were obtained by cloning the corresponding mouse cDNAs into pCanMycA vector (Onyx Pharmaceuticals, Emeryville, CA). Two polyclonal antibodies were generated by immunizing rabbits with bacterially expressed glutathione $S$-transferase (GST) fusions containing amino acids 1-168 and 1-261 of the mouse Ermin protein. A mouse monoclonal antibody (mAB 160) was raised against purified GST-Ermin (residues 1-261). Polyclonal antibodies were sequentially affinity purified using GST and the GST-Er$\min _{1-261}$ immobilized on agarose beads (Sigma, St. Louis, MO).

Northern blot and RNA in situ hybridization. Northern blot analysis and RNA in situ hybridization were performed as described previously (Spiegel et al., 2002). Multiple human tissues RNA samples (Clontech, Cambridge, UK) were hybridized with a radioactively labeled Ermin 
(KIAA1189) DNA fragment that comprised the entire human coding sequence. For developmental expression analysis, total RNA was isolated from rat brains at different times after birth and probed with a rat cDNA of Ermin coding sequence. In situ hybridization on brain and spinal cord sections was done using a cRNA probe corresponding to mouse Ermin.

Transfections and immunohistochemistry. Primary oligodendrocyte precursor cells and astrocytes were electoporated using the Amaxa (Gaithersburg, MD) technology according to the manufacturer's instructions. Immunocytochemistry and immunohistochemistry were performed as described previously (Poliak et al., 2003). The following antibodies were used: mouse anti-GFAP (Sigma), rat anti-MBP (Chemicon, Temecula, CA), mouse anti-CNP $\left(2^{\prime}, 3^{\prime}\right.$-cyclic nucleotide $3^{\prime}$-phosphodiesterase (Sigma), mouse anti- $\beta$-tubulin IV (Sigma), rabbit anti-Caspr (Gollan et al., 2002), hybridoma supernatants of mouse antibodies to RIP, O4, Ran2, A2B5, and mouse anti-myelin oligodendrocyte glycoprotein (MOG) Z12 (generous gift from N. Schaeren-Wiemers, University Hospital Basel, Basel, Switzerland). Immunoelectron microscopy was performed as described previously (Gollan et al., 2002).

Purification and culturing of oligodendrocyte precursor cells. Oligodendrocyte precursor cells were isolated by immunopanning from postnatal day 7 (P7) rat cortices essentially as described previously (Wang et al., 2001; Chan et al., 2004). Briefly, cells were negatively immunopanned using Ran 2 antibodies, followed by positive selection with $\mathrm{O} 4$ antibodies. Selected cells were expanded for $5 \mathrm{~d}$ in DMEM-Sato with PDGF A (10 ng/ml) and bFGF (basic fibroblast growth factor) $(10 \mathrm{ng} / \mathrm{ml})$. Differentiation was induced by the withdrawal of growth factors in Neurobasal/DMEM-Sato (50/50\%) medium supplemented with B27 (Invitrogen) and triiodothyroine $(40 \mathrm{ng} / \mathrm{ml})$. For microscopic analysis, cells were plated on poly-D-lysine-coated glass coverslips. A detailed protocol can be obtained on request.

\section{Results}

\section{Ermin is a novel oligodendrocyte-specific protein}

To find novel proteins important for CNS myelination, we searched for genes that are exclusively expressed in oligodendrocytes. To this end, we used microarray analysis to compare cDNAs from the brainstems of wild-type mice with those found in dysmyelinated mice expressing a diphtheria toxin in oligodendrocytes (Brockschnieder et al., 2004). Initial sequence analysis of one of the differentially expressed cDNAs suggested that it encodes for a novel cytoskeletal protein, herein referred to as Ermin. Cloning the mouse and rat Ermin cDNAs revealed that they contained open reading frames of 282 and 281 aa, respectively (GenBank accession numbers DQ334270 and DQ334271). The gene and its likely human ortholog are currently annotated in the National Center for Biotechnology Information Entrez Gene database under GeneId 77767 (mouse), GeneId 295619 (rat), and GeneId 57471 (human KIAA1189). The amino acid sequence of Ermin has limited similarity with the ERM (ezrin, radixin, moesin) proteins and may be considered as a distant member of this family (Bretscher et al., 2002; Ramesh, 2004) (Fig. 1A). All three

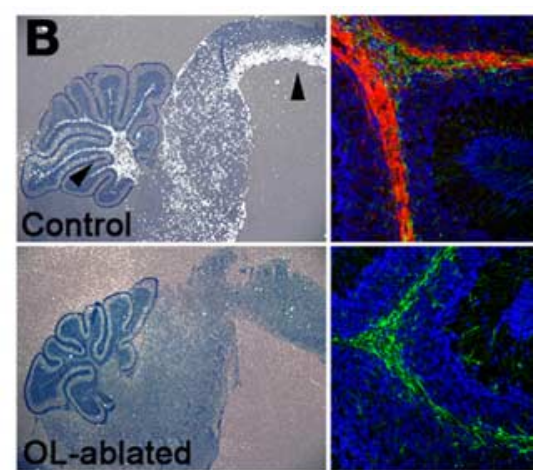

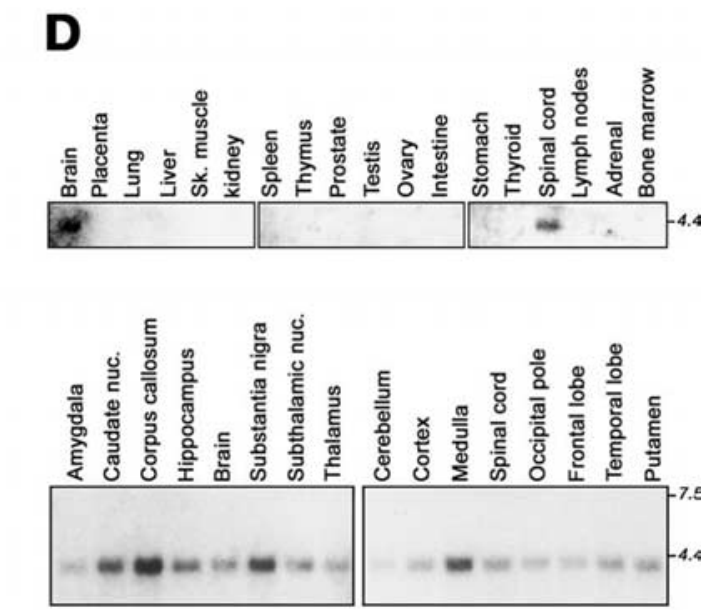

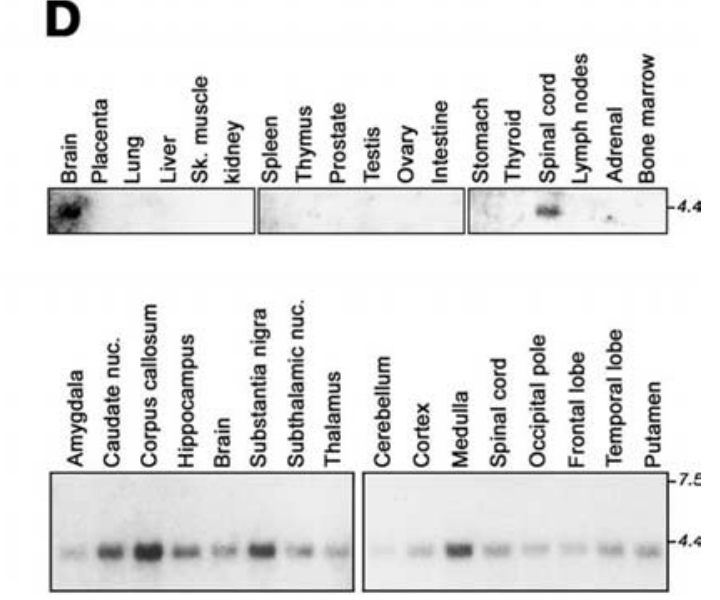

F-Actin

OL-ablated

Figure 1. Ermin is an oligodendrocyte-specific protein. $A$, Domain organization of Ermin compared with ERM proteins and protein 4.1. Ermin contains the C-terminal actin binding sequence but lacks the N-terminal FERM domain and the proline-rich sequence present in some other ERM proteins. B, Expression of Ermin in wild-type (control) and OL-ablated mice. In situ hybridNorthern blot hybridized with an Ermin-specific cDNA probe. E, Developmental Northern blot analysis of rat brain RNA. Note the increase in the expression of Ermin during the first 2 postnatal weeks.

ERM proteins contain a FERM (4.1, ezrin, radixin, moesin) domain at their $\mathrm{N}$ terminus, followed by a long helical coiled-coil region and a C-terminal filamentous (F)-actin binding site. Ermin lacks the N-terminal FERM domain, has a weak similarity along the $\alpha$-helical central region, but shares 18 almost identical amino acids with ERM proteins in their F-actin binding site (Bretscher et al., 2002; Ramesh, 2004).

In situ hybridization and immunofluorescence analyses of mouse brain and spinal cord, demonstrated that Ermin is expressed along white matter tracks (Fig. $1 B$, top). No signal was detected when OL-ablated brains were examined, consistent with the idea that Ermin is produced by oligodendrocytes (Fig. $1 B$, bottom). Double immunolabeling of brain sections or mixed CNS cultures using antibodies to Ermin and GFAP or neurofilaments showed that Ermin is not expressed by either astrocytes or neurons (Fig. 1B) (data not shown). Western blot analysis of brain lysates using an antibody to Ermin detected a $42 \mathrm{kDa}$ protein in wild-type, but not in OL-ablated brains (Fig. 1C), further indicating that Ermin is a prominent oligodendrocyte protein. Northern blot analysis using mRNA isolated from various tissues demonstrated the presence of a major $4.0 \mathrm{~kb}$ Ermin transcript in 

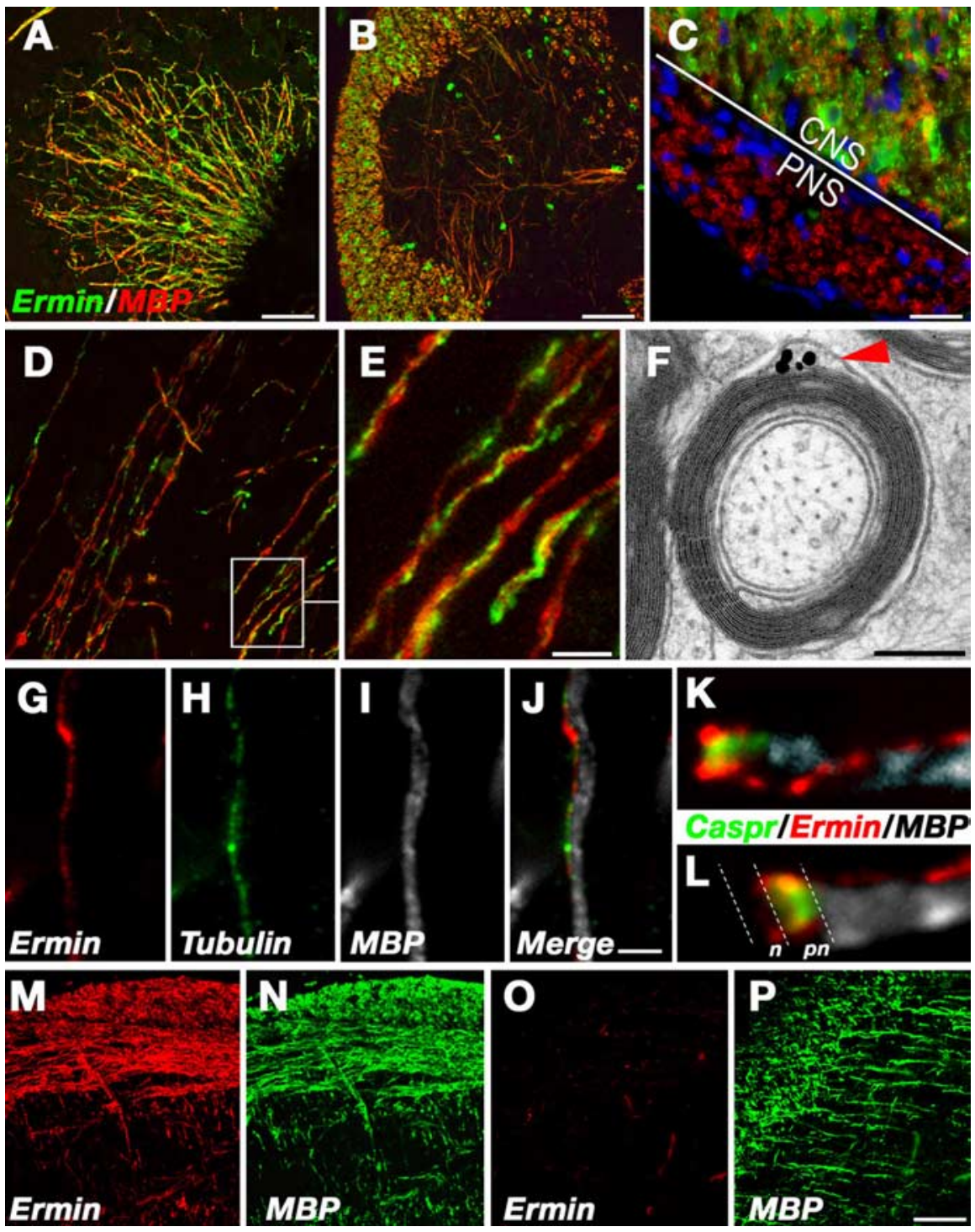

Figure 2. Expression and localization of Ermin in CNS myelin. $\boldsymbol{A}-\boldsymbol{E}$, Immunofluorescence labeling of sections through mouse cerebellum $(\boldsymbol{A})$, spinal cord $(\boldsymbol{B})$, ventral spinal cord with the adjacent spinal nerve $(\boldsymbol{C})$, and brainstem $(\boldsymbol{D}, \boldsymbol{E})$, using antibodies to Ermin (green) and MBP (red), as indicated. Note that Ermin is strongly expressed in spinal cord white matter (CNS) but not in

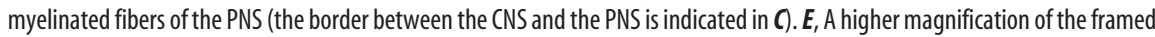
area in $\boldsymbol{D}$, showing that Ermin is concentrated in a line that spirals around compact myelin internodes. $\boldsymbol{F}$, Immunoelectron microscopy of cross sections of mouse optic nerves labeled with antibodies to Ermin. An intense signal is detected at the cytoplasmic pocket located between the compact myelin and the abaxonal (outer) membrane of the myelin sheath. $\mathbf{G}-\mathbf{J}$, Immunofluorescence staining of a single fiber with antibodies to Ermin (red), MBP (white), and $\beta$-tubulin IV (green) is shown along with the merged image. Note that Ermin colocalizes with $\beta$-tubulin IV at the outer lip of the myelin sheath. $\boldsymbol{K}, \boldsymbol{L}$, High magnification of the nodal region of a fiber labeled with Ermin (red), MBP (white), and Caspr (green). Note that the spiral of Ermin is connected to the cytoplasmic loops at the paranodes. The location of the nodes $(\mathrm{n})$ and paranodes $(\mathrm{pn})$ is labeled in $\boldsymbol{L}$. $\boldsymbol{M}-\boldsymbol{P}$, Developmental analysis. Sections containing the brainstem $(\boldsymbol{M}, \boldsymbol{N})$ or the corpus callosum and cortex $(\boldsymbol{O}, \boldsymbol{P})$ from a 10-d-old mouse were labeled with antibodies to Ermin (red) and MBP (green) as indicated. At P10, the vast majority of MBP-positive fibers in the brainstem already coexpress Ermin $(\boldsymbol{N})$, whereas in the cortex, most of the MBP-positive fibers are devoid of Ermin. Scale bars: $\boldsymbol{A}, \boldsymbol{B}, \boldsymbol{D}, \boldsymbol{M}-\boldsymbol{P}$, $100 \mu \mathrm{m} ; \mathbf{C}, 10 \mu \mathrm{m} ; \mathbf{G}-J, 2.5 \mu \mathrm{m} ; \boldsymbol{F}, 0.25 \mu \mathrm{m}$.

the brain and spinal cord, but not in other tissues (Fig. 1D). In the brain, strong expression of Ermin was detected in several whitematter-enriched tissues, such as the corpus callosum and medulla (Fig. $1 D$, bottom panel). During development, Ermin transcript was weakly detectable in the first 3 postnatal days, but increased dramatically during the initial 2 weeks after birth, a period when oligodendrocytes are actively myelinating axons in the CNS (Fig. $1 E)$. Lastly, in contrast to the robust expression of Ermin in oligodendrocytes (Figs. 1, 2), it was undetected in myelinating
Schwann cells of peripheral nervous system (PNS) tissues such as the sciatic nerve or the spinal roots (for example, see Fig. $2 C)$. Collectively, these results demonstrated that Ermin is a novel, cell-typespecific protein that is restricted to oligodendrocytes in the CNS and is absent from the PNS.

Ermin is localized in the outer cytoplasmic lip of the myelin sheath Immunofluorescence staining of adult mouse brain sections using Ermin-specific antibodies showed intense labeling of oligodendrocytes in all white matter tissues examined, including the cerebellum (Fig. $2 A$ ), spinal cord (Fig. $2 B, C$ ), and medulla (Fig. $2 D, E$ ). Ermin was present in oligodendrocyte cell bodies and processes and along myelinated fibers. At higher magnification, Ermin labeling appeared like a thread circling around the surface of MBPlabeled internodes (Fig. 2E). Immunoelectron microscopy of optic nerve sections using an affinity-purified Ermin antibody demonstrated that it was present in the abaxonal, cytoplasmic pocket of the myelin sheath, also referred to as the "outer tongue" or the "outer lip" (Fig. 2 F). No labeling was detected in compact myelin. In agreement, Ermin colocalized along the internodes with $\beta$-tubulin IV (Fig. $2 G-$ $J)$, which marks the outer cytoplasmic lip of the myelin sheath in the CNS (Terada et al., 2005). The internodal line of Ermin staining could be followed to the paranodal region (defined by the expression of Caspr), where it became diffusely distributed throughout the paranodal loops (Fig. $2 K, L)$. We thus concluded that, in mature myelinated nerves, Ermin is localized to noncompact myelin structures at the abaxonal and paranodal regions.

\section{Ermin appears late during \\ CNS myelination}

To determine when Ermin is expressed during myelination, we immunolabeled mouse brain cryosections obtained from different postnatal days (i.e., P1-P10) with antibodies to Ermin and MBP (Fig. $2 M-P$ ) (data not shown). We found that Ermin was always confined to MBP-labeled oligodendrocytes. Its expression followed the myelination process in a caudal-to-rostral and ventral-to-dorsal gradient, starting in the brainstem at $\mathrm{P} 1$, followed by the cerebellum and extending into the forebrain. However, the expression of Ermin lagged behind MBP by 2-3 d. During the early postnatal days, we could detect numerous newly myelinated MBP-positive fibers that lacked Ermin expression in all three regions (Fig. $2 \mathrm{O}$ for the cortex and corpus callosum). This analysis demonstrated that the expression of Ermin by oligodendrocytes commences relatively late during the myelination process. 
Ermin defines F-actin-rich spikes in differentiated oligodendrocytes

In culture, oligodendrocytes differentiate along a defined pathway, marked by a typical change in cell morphology and the expression of myelin-specific lipids and proteins (Pfeiffer et al., 1993). To further explore the role of Ermin in CNS myelination, we examined its expression during the differentiation of purified oligodendrocyte precursor cells (OPCs) (Fig. 3A$C)$. At different time points (1-12 d), cultures were immunolabeled with antibodies to Ermin and to various stagespecific markers for oligodendrocyte differentiation (A2B5, O4, GalC, RIP, MBP, MOG) (Baumann and Pham-Dinh, 2001). This analysis demonstrated that oligodendrocytes began to express Ermin not before $5 \mathrm{~d}$ after the induction of the differentiation process (Fig. $3 C$ ). In contrast, MBP was widely expressed already $3 \mathrm{~d}$ past induction, consistent with the observation that the expression of Ermin in vivo lagged behind that of MBP (Fig. 2O,P). Furthermore, double labeling with antibodies to Ermin and MOG (which marks mature oligodendrocytes) (Coffey and McDermott, 1997; Song et al., 2001) revealed the presence of numerous MOG-positive cells that had not yet expressed Ermin (data not shown), suggesting that Ermin can be considered as a new marker for very late stages of oligodendrocyte differentiation. Ermin was detected in short cellular spikes that were distributed throughout the cell but most prominently extended in high numbers from the cell body. The cell body itself and the MBP-labeled membranous sheet were almost devoid of Ermin (Fig. 3G). This pattern was strikingly distinct from any known oligodendrocytic marker (Fig. $3 D, E, G)$. Triple labeling for Ermin, $\mathrm{F}$-actin (phalloidin), and $\beta$-tubulin demonstrated that Ermin spikes were rich in F-actin. In more peripheral cell parts, Ermin often colocalized with the outer segments of F-actin harboring processes (Fig. $3 F, H$ ).

Ermin is an actin-binding protein that induces the formation of cell protrusions

To further examine whether Ermin might be involved in cytoskeletal reorganization, we transfected various cell lines, as well as primary OPCs and astrocytes with different expression constructs of Ermin. As depicted in Figure 4, $A-C$, ectopic expression of a full-length Ermin cDNA resulted in the induction of multiple cellular processes, branching, and a marked change in cell morphology in all cell types tested. Double labeling of transfected oligodendrocytes with an antibody to tubulin and fluorescent phalloidin, demonstrated that Ermin induced robust reorganization of F-actin (Fig. 4H,I). In these cells, Ermin was concentrated with $\mathrm{F}$-actin in numerous short cellular processes that emanate from the central tubulin-labeled branches. Domain-mapping
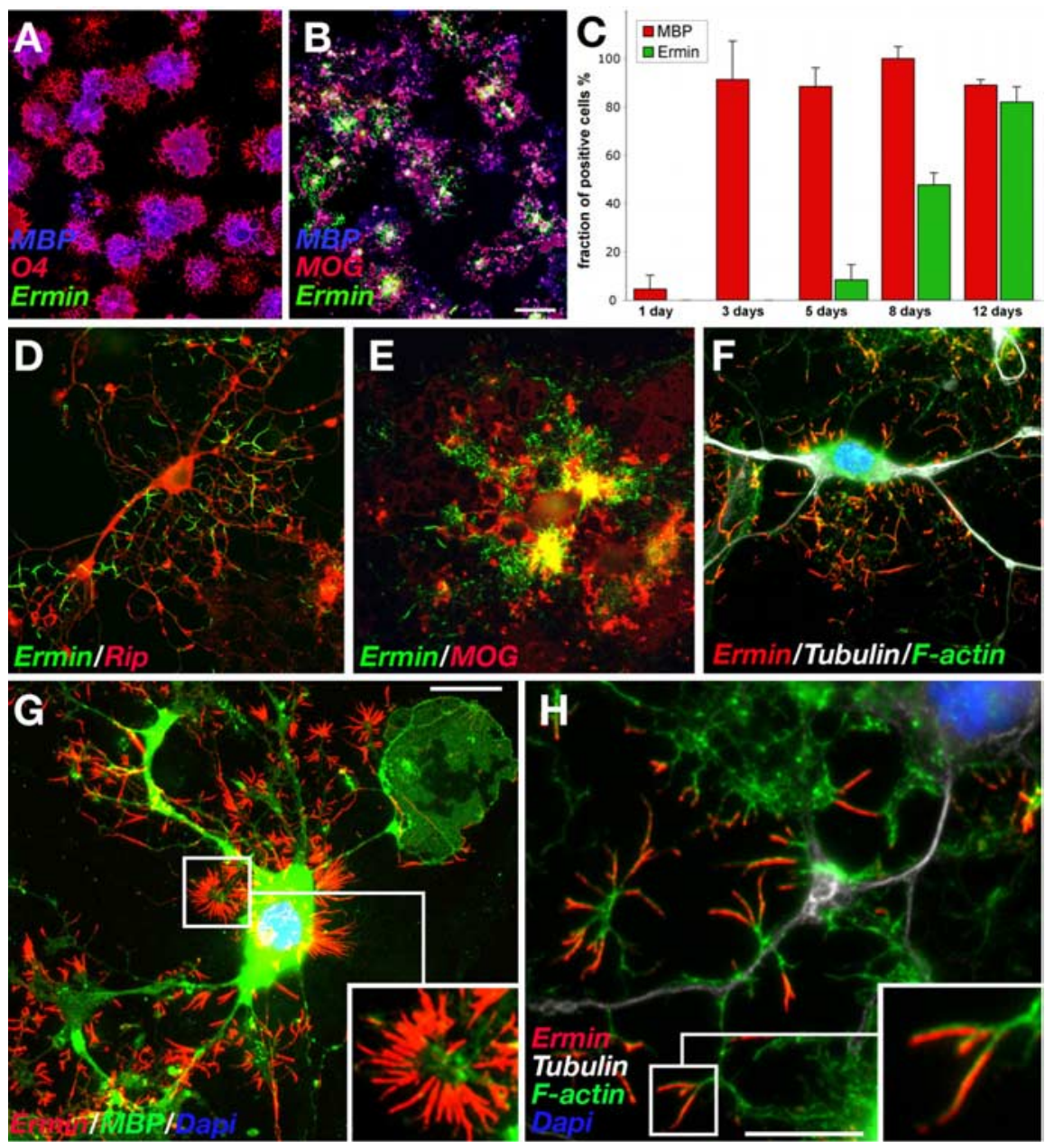

Figure 3. Ermin is expressed late during oligodendrocyte differentiation and is localized to $\mathrm{F}$-actin-containing spikes. $\boldsymbol{A}, \boldsymbol{B}$, Cultured OPCs grown for $3(\boldsymbol{A})$ or $12(\boldsymbol{B})$ days in differentiation media were immunolabeled for Ermin (green), MBP (blue) and 04 early $0 \mathrm{~L}$ marker; red in $\boldsymbol{A}$ ), or MOG (late $0 \mathrm{~L}$ marker; red in $\boldsymbol{B}$ ). At day $3(\boldsymbol{A})$, cells have already differentiated into MBP cytes at day $12(\boldsymbol{B})$. C, A bar graph showing the expression of Ermin during oligodendrocyte differentiation relative to MBP. At the Emin (red bars). The maximal number of MBP-positive cells on day 8 was arbitrarily set to $100 \%$. Error bars indicate the SD. Results ies to Ermin and $\operatorname{Rip}(\boldsymbol{D}), \operatorname{MOG}(\boldsymbol{E}), \operatorname{MBP}(\boldsymbol{G})$, or $\beta$-tubulin IV and phalloidin-A488 to visualize F-actin $(\boldsymbol{F}, \boldsymbol{H})$ as indicated. Note the striking accumulation of Ermin at the tips of $F$-actin-rich processes. The framed areas in $\boldsymbol{G}$ and $\boldsymbol{H}$ are shown at a higher magnification in the insets of each panel. Scale bars: $\boldsymbol{A}, \boldsymbol{B}, 100 \mu \mathrm{m} ; \boldsymbol{D}-\boldsymbol{G}, 10 \mu \mathrm{m} ; \boldsymbol{H}, 20 \mu \mathrm{m}$.

analysis further demonstrated that induction of cell extensions by Ermin required its C-terminal region, which contained its predicted actin-binding domain (Fig. $4 D-G$ ). Deletion of the last 20 C-terminal amino acids caused a diffuse cytoplasmic staining and abolished process induction, indicating that the function of Ermin depends on its ability to bind actin. In agreement, using an F-actin cosedimentation assay, we found that Ermin, but not the C-terminal deleted mutant, directly associates with F-actin (data not shown). These results demonstrate that the expression of Ermin causes substantial cytoskeletal rearrangements, supporting a role for this protein in regulating the dynamic morphological changes of oligodendrocytes during myelination.

\section{Discussion}

In the present study, we demonstrate that genetic cell ablation could be successfully combined with expression profiling to identify cell-type-specific genes. Using RNA isolated at the peak of 


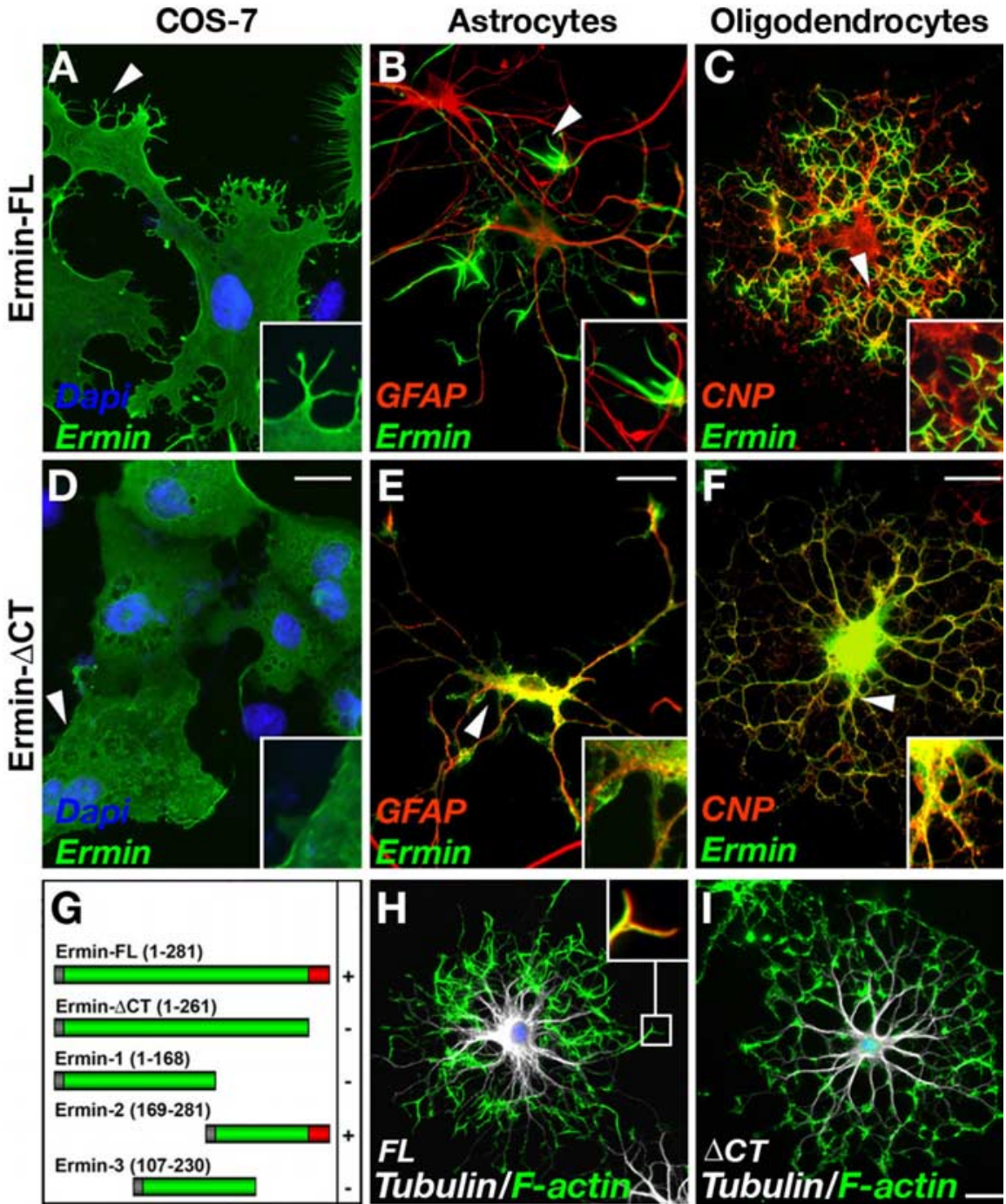

Figure 4. Ectopic expression of Ermin causes process outgrowth and redistribution of $F$-actin. $A-F, \operatorname{Cos}-7(A, D)$, astrocytes $(B$, $\boldsymbol{E})$, and oligodendrocyte precursor cells $(\boldsymbol{C}, \boldsymbol{F})$ were transfected with a full-length Ermin (Ermin-FL) $(\boldsymbol{A}-\boldsymbol{C})$ or Ermin mutant lacking its putative $C$ terminus actin-binding site $(\operatorname{Ermin} \Delta C T)(\boldsymbol{D}-\boldsymbol{F})$. Cells were immunolabeled $72 \mathrm{~h}$ later with the indicated antibodies; oligodendrocyte precursors were kept in differentiating medium during this time. Note that Ermin-FL, but not Ermin $\Delta C T$, induced multiple processes ( $\boldsymbol{A}, \boldsymbol{B}$, arrowheads). In transfected oligodendrocytes, Ermin is localized to fine processes and almost absent from major branches and the cell body, whereas Ermin $\Delta C T$ is diffusely distributed throughout the cytoplasm. $\boldsymbol{G}$, The ability of the indicated deletion mutants of Ermin to induce process formation in transfected $\operatorname{COS}-7$ cells is shown as $-/+. H, I$, Ermin induces redistribution of $\mathrm{F}$-actin. Oligodendrocyte precursor cells transfected with a full-length (FL) or a C-terminal-deleted ( $\triangle C T$ ) Ermin were immunolabeled using an antibody to $\beta$-tubulin IV (white) and phalloidin-A488 (green) to visualize $\mathrm{F}$-actin. $\boldsymbol{H}$, Inset shows a higher magnification of the boxed region stained for Ermin (red) and F-actin (green). Scale bars, $20 \mu \mathrm{m}$.

cytoskeleton. ERM proteins have been demonstrated to function upstream and downstream of Rho GTPases (Bretscher et al., 2002; Ramesh, 2004). It was suggested that Rho family GTPases function downstream of Fyn kinase to control process outgrowth and morphological changes during oligodendrocyte differentiation (Liang et al., 2004). Whether Ermin directly affects the activity of Rho family GTPases is thus of interest for future studies. Intriguingly, it has been shown that the activity of ERM proteins is regulated by intramolecular association between their $\mathrm{N}$ and $\mathrm{C}$ termini ends (Bretscher et al., 2002; Ramesh, 2004), raising the possibility that Ermin may function as an endogenous regulator of ERM proteins.

In the adult nerve, Ermin is found along the internodes in the cytoplasmic outer tongue of the myelin sheath and in the paranodal loops. Notably, at the paranodal region, Ermin immunoreactivity was distributed throughout the paranodal loops, and was not absent from the loops adjacent to the juxtaparanode, as was recently suggested for the rat ortholog of Ermin (termed Juxtanodin) (Zhang et al., 2005). In cultured oligodendrocytes, Ermin was absent in bipolar precursor cells, as well as in $\mathrm{RIP}^{+} \mathrm{O}_{4}^{+} \mathrm{GalC}^{+}$immature cells, and appeared first in well differentiated oligodendrocytes that already expressed RIP, MBP, and MOG. Hence, the unique expression of Ermin defines a new, previously unrecognized late stage of oligodendrocyte differentiation. Similarly, developmental immunofluorescence analysis of rodent brain sections using antibodies to Ermin and MBP, as well as other CNS myelin proteins, revealed that Ermin is starting to be expressed at a rather late stage of myelination. This might indicate that extrinsic, potentially axonal signals exist, which favor the expression of Ermin at a specific point during the myelination process. Staining for tubulin and F-actin

CNS myelin synthesis, we were able to identify a novel oligodendrocyte-specific protein we termed Ermin. Ermin shares a modular domain organization and functional characteristics with ERM proteins. It lacks the N-terminal FERM domain of ERMs, but the coiled domain is similar in length and the position of the F-actin domain at the $\mathrm{C}$ terminus is well conserved. Similar to other ERM proteins, Ermin binds to filamentous actin via a conserved peptide found at its $C$ terminus. In addition, the ability of Ermin to induce cellular processes is reminiscent of the ability of the other ERM proteins to affect cell morphology (Martin et al., 1997; Litman et al., 2000). ERM proteins are ubiquitously expressed proteins with dual functions; they cross-link membrane proteins to the cortical cytoskeleton and act in concert with Rho family GTPases as signal transducers in the regulation of the actin showed that in cultured oligodendrocytes, endogenous Ermin was accumulated in spikes at the tip of F-actin-rich processes ("Ermin spikes"). Although at present the in vivo significance of these spikes is not clear, they may represent a transient structure that is formed during process extension or retraction. In keeping with this idea, Ermin is specifically found in oligodendrocytes, which send numerous processes and form multiple myelin segments, but not in Schwann cells that usually give rise to a single myelin unit. Together, the restricted expression of Ermin in oligodendrocytes, its ability to bind and reorganize F-actin, and its late appearance during myelination point to a role of this protein in regulating cytoskeletal changes at the end of the wrapping and/or compaction phases of myelin assembly, as well as in maintenance and stability of the myelin sheath in the adult. 


\section{References}

Baumann N, Pham-Dinh D (2001) Biology of oligodendrocyte and myelin in the mammalian central nervous system. Physiol Rev 81:871-927.

Bretscher A, Edwards K, Fehon RG (2002) ERM proteins and merlin: integrators at the cell cortex. Nat Rev Mol Cell Biol 3:586-599.

Brockschnieder D, Lappe-Siefke C, Goebbels S, Boesl MR, Nave KA, Riethmacher D (2004) Cell depletion due to diphtheria toxin fragment A after Cre-mediated recombination. Mol Cell Biol 24:7636-7642.

Butt AM, Berry M (2000) Oligodendrocytes and the control of myelination in vivo: new insights from the rat anterior medullary velum. J Neurosci Res 59:477-488.

Chan JR, Watkins TA, Cosgaya JM, Zhang C, Chen L, Reichardt LF, Shooter EM, Barres BA (2004) NGF controls axonal receptivity to myelination by Schwann cells or oligodendrocytes. Neuron 43:183-191.

Coffey JC, McDermott KW (1997) The regional distribution of myelin oligodendrocyte glycoprotein (MOG) in the developing rat CNS: an in vivo immunohistochemical study. J Neurocytol 26:149-161.

Gollan L, Sabanay H, Poliak S, Berglund EO, Ranscht B, Peles E (2002) Retention of a cell adhesion complex at the paranodal junction requires the cytoplasmic region of Caspr. J Cell Biol 157:1247-1256.

Lappe-Siefke C, Goebbels S, Gravel M, Nicksch E, Lee J, Braun PE, Griffiths IR, Nave KA (2003) Disruption of Cnpl uncouples oligodendroglial functions in axonal support and myelination. Nat Genet 33:366-374.

Liang X, Draghi NA, Resh MD (2004) Signaling from integrins to Fyn to Rho family GTPases regulates morphologic differentiation of oligodendrocytes. J Neurosci 24:7140-7149.

Litman P, Amieva MR, Furthmayr H (2000) Imaging of dynamic changes of the actin cytoskeleton in microextensions of live NIH3T3 cells with a GFP fusion of the F-actin binding domain of moesin. BMC Cell Biol 1:1.

Martin M, Roy C, Montcourrier P, Sahuquet A, Mangeat P (1997) Three determinants in ezrin are responsible for cell extension activity. Mol Biol Cell 8:1543-1557.

Pfeiffer SE, Warrington AE, Bansal R (1993) The oligodendrocyte and its many cellular processes. Trends Cell Biol 3:191-197.

Poliak S, Salomon D, Elhanany H, Sabanay H, Kiernan B, Pevny L, Stewart CL, Xu X, Chiu SY, Shrager P, Furley AJ, Peles E (2003) Juxtaparanodal clustering of Shaker-like $\mathrm{K}^{+}$channels in myelinated axons depends on Caspr2 and TAG-1. J Cell Biol 162:1149-1160.

Ramesh V (2004) Merlin and the ERM proteins in Schwann cells, neurons and growth cones. Nat Rev Neurosci 5:462-470.

Song J, Goetz BD, Baas PW, Duncan ID (2001) Cytoskeletal reorganization during the formation of oligodendrocyte processes and branches. Mol Cell Neurosci 17:624-636.

Spiegel I, Salomon D, Erne B, Schaeren-Wiemers N, Peles E (2002) Caspr3 and caspr4, two novel members of the caspr family are expressed in the nervous system and interact with PDZ domains. Mol Cell Neurosci 20:283-297.

Terada N, Kidd GJ, Kinter M, Bjartmar C, Moran-Jones K, Trapp BD (2005) Beta IV tubulin is selectively expressed by oligodendrocytes in the central nervous system. Glia 50:212-222.

Wang S, Sdrulla A, Johnson JE, Yokota Y, Barres BA (2001) A role for the helix-loop-helix protein Id2 in the control of oligodendrocyte development. Neuron 29:603-614.

Wilson R, Brophy PJ (1989) Role for the oligodendrocyte cytoskeleton in myelination. J Neurosci Res 22:439-448.

Zhang B, Cao Q, Guo A, Chu H, Chan YG, Buschdorf JP, Low BC, Ling EA, Liang F (2005) Juxtanodin: An oligodendroglial protein that promotes cellular arborization and 2',3'-cyclic nucleotide-3'-phosphodiesterase trafficking. Proc Natl Acad Sci USA 102:11527-11532. 